\title{
Biophysical Reviews: 2020—looking back, going forward
}

\author{
Damien Hall ${ }^{1}$
}

Accepted: 26 November 2020 / Published online: 2 December 2020

(C) International Union for Pure and Applied Biophysics (IUPAB) and Springer-Verlag GmbH Germany, part of Springer Nature 2020

\begin{abstract}
After first describing the issue contents (Biophysical Reviews-Volume 12 Issue 6), this Editorial goes on to provide a short round-up of the activities of the journal in 2020. Directly following this Editorial are two obituaries marking the recent deaths of Prof. Fumio Oosawa (Japan) and Dr. Herbert Tabor (USA) - two major figures in Biophysical/Biochemical science from the last 100 years.
\end{abstract}

With the outbreak of the COVID-19 pandemic, 2020 has been a testing year for all. Filled with a myriad combination of personal tragedies and work/life inconveniences, circumstances have required many difficult decisions to be made at the personal, family, organizational and society levels with the results of these difficult choices amplifying the general level of stress within communities. Scientists have certainly not been immune from such pressures. For working scientists, this year has presented a number of challenges. Those scientists heavily involved in teaching have had to engage with remote teaching methodologies and the necessarily rapid preparation of additional online teaching materials. Research-focused scientists have had to cope with the closing or restriction of work facilities and the loss of personnel, which has certainly impacted (and often disrupted) scientific progress. For the many itinerant working scientists living away from home and family, the restrictions on worldwide travel have caused additional dilemmas and necessitated difficult career decisions. Student scientists have had to deal with other problems. Oftentimes educational institutions have maintained the steep fee requirements associated with enrolment despite the year being a virtual write-off in terms of focusing on academic performance. Overseas students have also faced problems related to maintaining interdependent attendance and residence requirements.

Irrespective of the stage of their career progression, scientists (like all members of society) have tried their best to make the most of a bad situation. In 2020, the Biophysical Reviews'

Damien Hall

hall.damien@nitech.ac.jp; damienhall30@gmail.com

1 Department of Life Sciences and Applied Chemistry, Nagoya Institute of Technology, Gokiso Showa, Nagoya 466-8555, Japan
Editorial Board and the specifically dedicated professional officers from Springer-Nature have similarly pushed on with our journal related duties. From 2018, Biophysical Reviews moved to a six Issue per year format. The current Issue (Issue 6) is the last for 2020, and as such, the first duty of this Editorial is to describe the contents of the twelve articles appearing within it. After providing a precis of these articles, we then move on to describe some of the highlights of this year and finish by welcoming some new members to the Editorial Board.

\section{Precis of articles in Issue 6}

Aside from the present Editorial (Hall 2020a), the front matter for this Issue consists of a sub-editorial, introducing Dr. Antonio Benedetto (one of the journal's Editorial Board Members) (Benedetto 2020) and two Commentaries (Maèda and Oda 2020; McPhie 2020), that respectively present obituaries for Dr. Fumio Oosawa and Dr. Herbert Tabor - two giants of the Biophysical/Biochemistry science scene. I had the good fortune to meet and spend some time with both of these scientists (about who these obituaries have been written) and highly recommend these interesting Commentaries written from both the scientific and human perspective. In my opinion, the authors do a remarkable job of providing the reader with a window into the lives of these very distinguished scientists, thereby providing worthy tributes.

Following the front material are eight topical review articles with the first two (Lavington and Watts 2020; Shechtman 2020) being requested contributions from the senior (Dr. Anthony Watts) and junior (Dr. Yoav Shechtman) winners of the IUPAB Investigator Awards for 2020. The article by Lavington and Watts (2020) describes how different membrane 
mimics can be used for the structural study of $G$ proteincoupled receptors (GPCRs) using solid-state NMR methods. As perhaps the most important class of integral membrane proteins, GPCRs carry out a number of different biological functions associated with cell growth, death and division, and are therefore much studied as possible pharmaceutical targets. Lavington and Watts (2020) describe their (and others) research on GPCRs using membrane nanoparticles, such as lipid nanodiscs and styrene maleic acid lipid particles (SMALPs) as structurally well-defined membrane-like environments having tuneable properties. The contribution by Shechtman (2020) provides a very readable introduction to the subject of superresolution microscopy before going on to detail the authors' contributions to the information processing aspects of this field of microscopy. Starting with a mathematical description of the point spread function the author details how suitable treatment of the signal can result in near nanometre level assignment of details present within biological specimens (2020).

Following these two award-related contributions are six invited reviews on a disparate range of topics. The first of these (Rajendra and Brahmajirao 2020) is concerned with the use of artificial intelligence (AI) and machine learning (ML) methods for the analysis of dynamical/time series data. Whilst the scientific community is becoming familiar with $\mathrm{AI} / \mathrm{ML}$ for the processing of static information (such as image/structural analysis; face recognition), they are perhaps less aware of the use of such procedures for the processing of time series data. In this article, Rajendra and Brahmajirao (2020) do a good job of describing how coupling of intermediate numerical methods based on differential equations can be used to fill the static to dynamic AI/ ML information processing 'gap'.

The next review article, contributed by Mizuguchi and Nuriya (2020), describes recent developments in second harmonic generation (SHG)/sum frequency generation (SFG) methodologies. Revolving around two-photon superposition/ joint action principles, the authors utilize Jablonski-type diagrams to describe the optical physics, walking the reader through the history and recent developments in the field with an emphasis on the use of these techniques for characterization of biological events occurring within the cellular plasma membrane. This article by Mizuguchi and Nuriya (2020) serves both as an excellent primer on the optical phenomenon and a good survey of its recent application to create superior biological imaging techniques.

The following article by Kumar et al. (2020) is concerned with the pathogenically important calcium binding proteins of the amoeba, E. histolytica, associated with causing the human diseases of colitis and dysentery. The authors review threedimensional structural information gained on the nearly thirty known $E$. histolytica calcium-binding proteins which show

\footnotetext{
${ }^{1}$ Calmodulin $(\mathrm{CaM})$ is a highly conserved protein existing throughout the eukary super-kingdom.
}

some degree of acid sequence similarity to calmodulin $(\mathrm{Ca}-$ $\mathrm{M}){ }^{1}$ Kumar et al. propose arguments tying the apparent structural diversity seen within the amoebic calcium-binding protein family to apparent functional diversity required for interaction with different partner proteins present across a range of signalling and regulatory pathways (Kumar et al. 2020).

The next Review, by Pratt et al. (2020), continues with the calcium theme by focusing on the role that this divalent cation plays in the regulation of breast cancer development. This well-written review article spends considerable effort on the scientific history of the discovery of calcium's role in cell signalling. Focusing on quantitative aspects, the authors discuss the action of calcium ions on various signalling pathways as a function of the amplitude, frequency and spatial characteristics of the calcium ion levels. Reviewing both the analytical methodology and the biological 'circuitry' affected by calcium, this article discusses how cancerous cells can exploit aberrant calcium regulation to direct cancer specific cell fates involving growth or metastases (Pratt et al. 2020).

The penultimate review deals with recent developments in the biophysics and biomechanics of the machine/muscle interface (Gohel and Mehendale 2020). Treating both the equipment required for recording electrical activity occurring within the muscle, and the algorithms required for signal deconvolution and subsequent completion of the transduction to electronic or mechanical output, the article by Gohel and Mehendale (2020) provides the reader with a very readable glimpse into human's ever closer relationship with machines, with such technology proffering both smoother machine control and hope for restoration of quality of life for those suffering injuries.

The final contribution to this last Issue of Biophysical Reviews for 2020 is a highly focused review article on the nucleic acid binding properties of the plant alkaloid chelerythrine (Basu and Suresh 2020). As a relatively small molecule, chelerythrine and its alkaloid derivatives/analogues, show intriguing binding specificity with regard to type (DNA vs RNA), strand (single vs. double vs. triple) and sequence (base vs. short sequence) and as such suggests itself for possible usage in the construction of molecular tools used in biology and medicine. After reviewing a large number of biophysical studies, Basu and Suresh (2020) explore this latter aspect, reviewing chelerythrine's potential as an anticancer drug candidate.

\section{Highlights of 2020}

The six Issues of Biophysical Reviews in 2020 consisted of two Special Issues and four regular Issues. This year saw over hundred and sixty articles published. Here I provide a (very) short flavour of some of the diverse set of topics covered in each Issue. 
Issue 1 started off with equal parts hope and sadness with the respective announcement of the inaugural winner of the Michèle Auger winner (Dr. Alexandra Zidovska) (Hall 2020b) and the obituary for Dr. Christopher M. Dobson (Dumoulin 2020). Some of the interesting review articles in Issue 1 included those on the topics of hybrid biosynthetic strategies (Alissandratos 2020), dramatic effects of proline substitution on protein structural propensities (Ganguly and Basu 2020), computational studies of the interaction of urea with protein interfaces (Raghunathan et al. 2020) and the use of the differential scanning fluorimetry (DSF) for high throughput drug candidate screening (Gao et al. 2020).

Issue 2 saw the first instalment of the Biophysical Reviews partnership program with various countries' national biophysical societies that is aimed at providing readers with a closer look at the biophysical research and organizational structures in place within a particular country. In Issue 2, we explored the Biophysical Society of Japan (BSJ) (Komatsuzaki et al. 2020; Hall 2020c). The front matter contained within it numerous fascinating Commentaries about the BSJ's organizational units which included contributions by the executive officers (Harada 2020; Akiyama 2020; Miyata 2020; Nakamura 2020), Japanese biophysical journal Editors (Sako 2020; Ishiwata 2020a, b) and five consortiums describing biophysical research at various national centres and universities (Aizawa et al. 2020; Akiyama et al. 2020a, b; Ando 2020a, b; Takano et al. 2020). This section was further complemented by contributions from senior (Kataoka 2020) and junior members (Okamoto 2020).

The bulk of the Special Issue was composed of numerous review articles (forty-five) chosen from the nearly thirty separate sections of the BSJ's national society meeting. A short selection of these (many) interesting review articles includes those dealing with the biophysics of chromatin (Ashwin et al. 2020; Kumar and Kono 2020); optogenetics (Kandori 2020); computational structure prediction (Kinoshita and Hayashi 2020; Leitner and Yamamoto 2020; Tsuchiya and Tomii 2020); physical biochemistry (Tsumoto et al. 2020); molecular motors (Li and Toyabe 2020; Loutschko and Flechsig 2020; Noji et al. 2020); membrane protein interaction (Moghal et al. 2020); novel scattering, structural and imaging techniques (Nakasako et al. 2020; Uchihashi and Ganser 2020; Yamaoki et al. 2020; Yokoyama et al. 2020); cellular biophysics (Okazaki et al. 2020; Yasuda 2020); biophysical thermochemistry (Fukuyama and Maeda 2020; Suzuki and Plakhotnik 2020); and biophysical theory (Leitner and Yamamoto 2020; Uda 2020).

Volume 12 Issue 3 (Hall 2020d) was a regular Issue that contained eleven articles. With no set theme, the contributed articles covered a range of topics with some of the highlight review pieces dealing with Brillouin microscopy (Antonacci et al. 2020); cellular imaging using atomic force microscopy (Zapotoczny et al. 2020); and exploration of novel second messenger systems (Petchiappan et al. 2020) and laboratory based studies of evolution (Horinouchi and Furusawa 2020).

Issue 4 was the second scheduled Special Issue for 2020 (Hall et al. 2020). Titled 'Biophysics of Human Anatomy and Physiology', this festschrift collected articles related to the biophysics of physiological processes (particularly related to the heart) for the occasion of the $80^{\text {th }}$ birthday of Dr. Cristobal dos Remedios. A powerhouse of biophysical research, both in Australia and on the international stage, Cristobal dos Remedios was long active within IUPAB and was also a former Chief Editor of Biophysical Reviews (dos Remedios 2020). Over a fifty-five year career Cris made important breakthroughs in both the molecular understanding of muscle function (through his pioneering studies on Förster resonance energy transfer experiments of actin myosin structural relations) as well as the general design and execution of cardiac muscle biophysical research (through the establishment of the Sydney Heart Bank). This Special Issue saw over forty-two contributions from scientific collaborators and peers accrued over his long career. The front material of the Issue contained a number of personal and scientific Commentaries addressing various stages of Cris' life (Hall et al. 2020; Ishiwata 2020a, b; van Dijk 2020; Li 2020). The bulk of the scientific content of this Issue was constituted by twenty-two topical review articles that spanned different areas of cardiac research. Some particularly noteworthy examples dealt with growth factor directed therapy for cardiac muscle repair (White and Chong 2020); cardiomyocyte fluoresce-based microscopy methods (Janco et al. 2020; Pandzic et al. 2020; Hassan et al. 2020); cellular mechano-transduction and shape determinants on cell growth regulation (Esfahani and Knöll 2020; Pruna and Ehler 2020; Harley et al. 2020); synthetic biology approaches to the study of motor proteins (Linke et al. 2020); use of plasma technology in surgical equipment surface treatment (Harley et al. 2020); and the regulatory pathways and structural roles of profilin (Davey and Moens 2020).

Containing twenty articles, Volume 12 , Issue 5 , was the third regular-type Issue of 2020 for Biophysical Reviews (Hall, 2020-e). A feature of this Issue was the invited review article by Dr. Alexandra Zidovska, the inaugural winner of the Michèle Auger award for young scientists' independent research (Hall 2019a, b; IUPAB 2018). In her award article Alexandra reviewed salient material within her thematic topic of cytosol rheology (Zidovska 2020). In addition, her article carried two short personal biographies of both herself and Michele Auger - the scientist and former Biophysical Reviews Editorial Board Member for whom the award acts as a perpetual memorial. Issue 5 also included contributions on topics covering the evolution of the cellular unit (Kundu et al. 2020); theoretical constraints to evolution (Furusawa and Irie 2020); single particle approaches to the study of virus particles (Kiss et al. 2020); and cryo-preparation methods for electron and mixed microscopy imaging methodologies (Yusuf et al. 2020). 
Table 12020 Biophysical Reviews Editorial Board

Chief Editor

Damien Hall

Visiting International Scientist Program, Nagoya Institute of Technology (Japan)

Emeritus Chief Editors

Cristobal dos Remedios

Jean Garnier

Executive Editors

J.W. K. Ho

R. Itri

N. R. Jagannathan

K. Nagayama

W. Olson

SI Editors 2020

Tamiki Komatsuzaki, Hokkaido University

Takeharu Nagai, Osaka University

Haruki Nakamura, Osaka University

Kuniaki Nagayama, Institute for Molecular Sciences, Okazaki

Jeremy Tame, Yokohama City University

Saeko Yanaka, Institute for Molecular Sciences, Okazaki

Amy Li, La Trobe University

Damien Hall, Nagoya Institute of Technology

Roger Cooke, University of California, Davis

Editorial Board Members

\section{J. Alegre-Cebollada}

T.W. Allen

J. Baenziger

E. Baulieu

A. Benedetto

P. Ciancaglini

D. Crossman

P.J. Cozzone

E.M. De La Cruz

D. Devaurs

E.J. Dufourc

E. Ehler

L. Finzi

J. C. Gómez-Fernández

S.J. Harding

J. Higo

P. Karthe

A.R. Kinjo

J. Kozelka

T. Kraft

K. K. Kim

A. $\mathrm{Li}$

S. Leslie

B. Maggio

B. Martinac

J.W. McNamara

M.M. Morales

H. Nakamura
Department of Medicine, University of Sydney, Australia

International Science Council, France

Li Ka Shing Faculty of Medicine, The University of Hong Kong, China

Institute of Physics, University of Sao Paolo, Sao Paolo, Brazil

Department of NMR \& MRI, All India Institute of Medical Sciences, India

National Institute for Physiological Sciences, Okazaki, Japan

Department of Chemistry and Chemical Biology, Rutgers University, USA

Special Issue on the Biophysical Society of Japan (BSJ)_-Miyazaki Meeting, September, 2019

Biophysics of Human Anatomy and Physiology - a Special Issue in honour of Prof. Cristobal dos Remedios's $80^{\text {th }}$ birthday

Centro Nacional de Investigaciones Cardiovasculares, Spain

Royal Melbourne Institute of Technology, Victoria Australia

University of Ottawa, Canada

Institut National de la Santé et de la Recherche Médicale Le Kremlin-Bicêtre, France

University College Dublin, Dublin, Ireland

Universidade de São Paulo, Ribeirao Preto - SP, Brazil

University of Auckland, New Zealand

Université de la Méditerranée, Marseille, France

Yale University, New Haven, CT, USA

INRIA, Grenoble, France

University of Bordeaux, France

University of London King's College, London, England

Emory University, Atlanta, Georgia, USA

University of Murcia, Murcia, Spain

University of Nottingham, England

University of Hyogo, Japan

CAS in Crystallography and Biophysics, University of Madras, India

Department of Mathematics, Universiti Brunei Darussalam, Brunei

University Paris Diderot, France \& Masaryk University, Brno, Czech Republic

Hannover Medical School, Germany

Sungkyunkwan University, Republic of Korea

Latrobe University, Melbourne, Australia

McGill University, Canada

Universidad Nacional de Córdoba, Córdoba, Argentina

Victor Chang Cardiac Research Institute, Australia

University of Cincinnati, Ohio, USA

Cidade Universitária, Rio de Janeiro, Brazil

Institute of Protein Research, Osaka University, Osaka, Japan 
Table 1 (continued)

Chief Editor

\begin{tabular}{|c|c|}
\hline Damien Hall & Visiting International Scientist Program, Nagoya Institute of Technology (Japan) \\
\hline H. Noji & The University of Tokyo, Tokyo, Japan \\
\hline R.D. Peluffo & University of the Republic, Uruguay \\
\hline P. Pohl & University Linz, Linz, Austria \\
\hline M. Prietto & University of Lisbon, Portugal \\
\hline K. Radotic & University of Belgrade, Serbia \\
\hline C.M. Rao & Centre for Cellular and Molecular Biology, India \\
\hline Z. Rao & Tsinghua University, China \\
\hline C. Royer & Rensselaer Polytechnic Institute, Troy, NY, USA \\
\hline F. Separovic & University of Melbourne, Australia \\
\hline B. T. Sewell & University of Cape Town, Cape Town, South Africa \\
\hline K. Shearwin & Molecular and Biomedical Science, University of Adelaide, Australia \\
\hline A. Shonhai & University of Venga, South Africa \\
\hline C.M. Soares & Universidade Nove de Lisboa, Oeiras, Portugal \\
\hline A.H. Squires & University of Chicago, USA. \\
\hline D. Szczesna-Cordary & University of Miami, FL, USA \\
\hline J. Tame & Yokohama City University, Japan \\
\hline S. del Valle Alonso & Universidad Nacional de Quilmes, Argentina \\
\hline J. van der Velden & VU University Medical Center, The Netherlands \\
\hline M. Vassalli & University of Glasgow, Scotland \\
\hline M. Williams & Massey University, New Zealand \\
\hline G.J.L. Wuite & VU University Amsterdam, The Netherlands \\
\hline K. Yasuda & Waseda University, Tokyo, Japan \\
\hline B. Zapotoczny & Institute of Nuclear Physics, Polish Academy of Sciences, Poland \\
\hline A. Zidovska & New York University, USA \\
\hline G. Zucchelli & Università degli Studi di Milano, Italy \\
\hline
\end{tabular}

\section{Biophysical reviews' meet the editors series}

In 2020 the journal started including within each Issue a short biographical sketch of members of the Editorial Board. The first five Issues of Volume 12 concentrated on introducing the five internationally based Executive Editors. Provided by Wilma Olson, based in the USA (Olson 2020), Kuniaki Nagayama (Japan) (Nagayama 2020), Naranamangalam Jagannathan (India) (Jagannathan 2020), Joshua Ho (Hong Kong, China) (Ho 2020) and Rosangela Itri (Brazil) (Itri, 2020), these articles can additionally serve the readership by providing an easy point of access to a senior Editor in your geographic location. In the final Issue of the year we started introducing regular members of the Editorial Board, with the first being Antonio Benedetto based in Ireland (Benedetto 2020). With over 40 international members constituting the Biophysical Reviews' Editorial Board, we envisage that this 'Meet the Editors Series' will continue for a number of years to come!

\section{Social media}

This year saw the continuing success of Biophysical Reviews social media program. ${ }^{2}$ Consisting of a Twitter ${ }^{\mathrm{TM}}$ feed and a YouTube $^{\mathrm{TM}}$ channel, Biophysical Reviews does its utmost to utilize its social media arm to provide authors with postpublication promotional opportunities. In doing so, we ask authors to exploit the Springer-Nature SharedIt ${ }^{\mathrm{TM}}$ tool- a device that enables free posting and sharing of published content across any internet platform (Hall 2017, 2019a, b). The journal's social media sites can be accessed at the following web addresses.

\section{Biophysical reviews YouTube channel}

https://www.youtube.com/channel/UCzG_ 5MWmnrB2UBibtxs2DuA

\footnotetext{
${ }^{2}$ Despite a two month hiatus of the Twitter feed due to a security 'incident'.
} 


\section{Biophysical reviews twitter account}

\author{
@BiophysicalRev1
}

\section{Concluding remarks and hopes for 2021}

Developed by IUPAB as a vehicle to help promote biophysical research and education at the international, national and community levels, Biophysical Reviews has increased its published output and philanthropic activities during 2020. The many benefits of focusing on review content have been expounded upon within the journal (Hall 2019a, b). As evidenced by the latest journal metrics, Biophysical Reviews has continued to develop since its inception in 2009 (Scimago 2020). Now ranked $11^{\text {th }}$ amongst journals in the biophysics section and having a Q1 rating in both the biophysics and structural biology groups, Biophysical Reviews is one of the top platforms for publishing biophysics-related content. A journal such as Biophysical Reviews (that operates on an invitation contribution model) is very much the sum of its Editorial Board Members. As such, I would like to thank the existing members of the Editorial Board (Table 1) for their efforts throughout the year. It is also my pleasure to welcome new members to the Board for 2021 (new members shown in bold in Table 1). It is with fervent hope that the situation in 2021 improves for the better, and on behalf of the journal, I would like to wish all readers and contributors the very best for the coming year.

Postscript Prospective authors interested in submitting a review article to Biophysical Reviews are encouraged to first broach the matter with either the Chief Editor or their local Executive or Editorial Board Member. After discussion on the suitability of their article a timetable for their submission will be arranged in conjunction with the professional officers of the journal.

Acknowledgements DH acknowledges the Nagoya Institute of Technology for an appointment to their 'Visiting International Scientist' program carried out at the Department of Life Science and Applied Chemistry.

\section{References}

Aizawa T, Demura M, Gohara K, Haga H, Ishimori K, Kinjo M, Komatsuzaki T, Maenaka T, Yao M (2020) Biophysical research in Hokkaido University, Japan. Biophys Rev 12(2):233-236

Akiyama S (2020) Treasurer's comments on the financial position of the biophysical Society of Japan. Biophys Rev 12(2):209-211

Akiyama R, Annaka M, Kohda D, Kubota H, Maeda Y, Matsumori N, Mizuno D, Yoshida N (2020a) Biophysics at Kyushu University. Biophys Rev 12(2):245-247
Akiyama S, Aoki K, Kubo Y (2020b) Biophysical research in Okazaki, Japan. Biophys Rev 12(2):237-243

Alissandratos A (2020) In vitro multi-enzymatic cascades using recombinant lysates of E. coli: an emerging biocatalysis platform. Biophys Rev 12(1):175-182

Ando T (2020a) Biophysics in Kanazawa University. Biophys Rev 12(2): 249-251

Ando T (2020b) Studies on the impellers generating force in muscle. Biophys Rev 12(4):767-769

Antonacci G, Beck T, Bilenca A, Czarske J, Elsayad K, Guck J, Kim K, Krug B, Palombo F, Prevedel R, Scarcelli G (2020) Recent progress and current opinions in Brillouin microscopy for life science application. Biophys Rev 12(3):615-624

Ashwin SS, Maeshima K, Sasai M (2020) Heterogeneous fluid-like movements of chromatin and their implications to transcription. Biophys Rev 12(2):461-468

Basu A, Suresh KG (2020) Interaction of the putative anticancer alkaloid chelerythrine with nucleic acids: biophysical perspectives. Biophys Rev 12(6) current issue

Benedetto A (2020) From just physics to biophysics of biological systems. Biophysical Reviews 12(6) Current Issue

Davey RJ, Moens PDJ (2020) Profilin: many facets of a small protein. Biophys Rev 12(4):827-834

dos Remedios C (2020) A career in biophysics. Biophys Rev 12(4):741-745

Dumoulin M (2020) Reflections on professor sir Christopher M. Dobson (1949-2019). Biophys Rev 12(1):13-18

Esfahani PH, Knöll R (2020) Cell shape: effects on gene expression and signalling. Biophys Rev 12(4):895-901

Fukuyama T, Maeda YT (2020) Opto-thermal diffusiophoresis of soft biological matters: from physical principle to molecular manipulation. Biophys Rev 12(2):309-315

Furusawa C, Irie N (2020) Toward understanding of evolutionary constraints: experimental and theoretical approaches. Biophys Rev 12(5):1151-1161

Ganguly HK, Basu G (2020) Conformational landscape of substituted prolines. Biophys Rev 12(1):25-39

Gao K, Oerlemans R, Groves MR (2020) Theory and applications of differential scanning fluorimetry in early-stage drug discovery. Biophys Rev 12(1):85-104

Gohel V, Mehendale N (2020) Review on electromyography signal acquisition and processing. Biophysical Reviews 12(6) Current Issue

Hall D (2017) Innovations in publication: free sharing of all biophysical reviews' content. Biophysical Reviews 9:67-68

Hall D (2019a) Biophysical reviews enters the online world, provides a focus on biophysics in Asia. Biophys Rev 11:249-250

Hall D (2019b) The benefits of writing a review. Biophys Rev 11:663666

Hall D. (2020a) Biophysical reviews: 2020 - looking back, going forward. Biophysical Reviews, 12(6), Current Issue

Hall D (2020b) A new decade for Biophysical Reviews and a look into the future of biophysics. Biophysical Reviews 12(1):1-7

Hall D (2020c) Biophysical reviews' national biophysical society partnership program. Biophysical Reviews 12(2):187-192

Hall D (2020d) Biophysical reviews - quantitative analysis of biological phenomenon. Biophysical Reviews 12(3):601-605

Hall D, Li A, Cooke R (2020) Biophysics of human anatomy and physiology - a Special Issue in honor of Prof. Cristobal dos Remedios on the occasion of his $80^{\text {th }}$ birthday. Biophys Rev 12(4):731-739

Harada Y (2020) Greetings from the President of the Biophysical Society of Japan. Biophys Rev 12(2):201-203

Harley JC, Suchowerska N, McKenzie DR (2020) Cancer treatment with gas plasma and with gas plasma-activated liquid: positives, potentials and problems of clinical translation. Biophys Rev 12(4):9891006 
Hassan S, Barrett CJ, Crossman DJ (2020) Imaging tools for assessment of myocardial fibrosis in humans: the need for greater detail. Biophys Rev 12(4):969-987

Ho JWK (2020) Biophysical Review's "Meet the editors series"- a profile of Joshua WK Ho. Biophys Rev 12(4):745-748

Horinouchi T, Furusawa C (2020) Understanding metabolic adaptation by using bacterial laboratory evolution and trans-omics analysis. Biophys Rev 12(3):677-682

Ishiwata S (2020a) On the on-line journal "Biophysics and Physicobiology (BPPB)". Biophys Rev 12(2):217-219

Ishiwata S (2020b) Research exchange with Cris: from fluorescence spectroscopy to human myocardium. Biophys Rev 12(4):773-775

IUPAB (2018) Newsletter, issue 70 (February). http://iupab.org/2018/11/ 06/obituary-michele-auger-former-iupab-councilor/

Jagannathan NR (2020) Biophysical reviews' "Meet the editors series" a profile of Naranamangalam R Jagannathan. Biophys Rev 12(3): 607-614

Janco M, Dedova I, Bryce NS, Hardeman EC, Gunning PW (2020) Visualizing the in vitro assembly of tropomyosin/actin filaments using TIRF microscopy. Biophys Rev 12(4):879-885

Kandori H (2020) Biophysics of rhodopsins and optogenetics. Biophys Rev 12(2):355-36

Kataoka M (2020) Biophysical Society of Japan, 45years ago. Biophys Rev 12(2):207-208

Kinoshita M, Hayashi T (2020) Accurate and rapid calculation of hydration free energy and its physical implication for biomolecular functions. Biophys Rev 12(2):469-480

Kiss B, Mudra D, Török G, Mártonfalvi Z, Csík G, Herényi L, Kellermayer M (2020) Single particle virology. Biophys Rev 12(5):1141-1154

Komatsuzaki T, Nakamura H, Tame J, Yanaka S, Nagai T, Nagayama K (2020) Editorial for the special issue of biophysical reviews focused on the biophysical Society of Japan with select scientific content from the $57^{\text {th }}$ BSJ annual meeting, Miyazaki, Japan. Biophys Rev 12(2):183-185

Kumar A, Kono H (2020) Heterochromatin protein 1 (HP1): interactions with itself and chromatin components. Biophys Rev 12(2):387-400

Kumar S, Mishra S, Gourinath S (2020) Structural and functional diversity of Entamoeba histolytica calcium-binding proteins. Biophysical Reviews 12(6) Current Issue

Kundu N, Mondal D, Sarkar N (2020) Dynamics of the vesicles composed of fatty acids and other amphiphile mixtures: unveiling the role of fatty acids as a model protocell membrane. Biophys Rev 12(5):1117-1131

Lavington S, Watts A (2020) Lipid nanoparticle technologies for the study of $\mathrm{G}$ protein-coupled receptors in lipid environments. Biophysical Reviews 12(6) Current Issue

Leitner DM, Yamato T (2020) Recent developments in the computational study of protein structural and vibrational energy dynamics. Biophys Rev 12(2):323-332

Li A (2020) Cris dos Remedios: Sydney Heart Bank and scientific mentorship beyond 2010. Biophys Rev 12(4):763-764

Li C, Toyabe S (2020) Efficiencies of molecular motors: a comprehensive overview. Biophys Rev 12(2):419-423

Linke H, Höcker B, Furuta K, Forde NR, Curmi PMG (2020) Synthetic biology approaches to dissecting linear motor protein function: towards the design and synthesis of artificial autonomous protein walkers. Biophys Rev 12(4):1041-1054

Loutschko D, Flechsig H (2020) Allosteric communication in molecular machines via information exchange: what can be learned from dynamical modeling. Biophys Rev 12(2):443-452

Maèda Y, Oda N (2020) Obituary Fumio Oosawa 1922-2019. Biophysical Reviews 12(6) Current Issue

McPhie P (2020) Herbert Tabor (1918 - 1920): obituary. Biophysical Reviews 12(6) Current Issue
Miyata M (2020) Current status of the website of the biophysical Society of Japan. Biophys Rev 12(2):213-214

Mizuguchi T, Nuriya M (2020) Applications of second harmonic generation (SHG)/sum-frequency generation (SFG) imaging for biophysical characterization of the plasma membrane. Biophysical Reviews 12(6) Current Issue

Moghal MMR, Hossain F, Yamazaki M (2020) Action of antimicrobial peptides and cell-penetrating peptides on membrane potential revealed by the single GUV method. Biophys Rev 12(2):339-348

Nagayama K (2020) Biophysical reviews' "Meet the Editors Series"- a profile of Kuniaki Nagayama: encounters and leaps in a transborder journey through biophysics. Biophys Rev 12(2):193-199

Nakamura H (2020) Big data science at AMED-BINDS. Biophys Rev 12(2):221-224

Nakasako M, Kobayashi A, Takayama Y, Asakura K, Oide M, Okajima K, Oroguchi T, Yamamoto M (2020) Methods and application of coherent X-ray diffraction imaging of noncrystalline particles. Biophys Rev 12(2):541-567

Noji H, Ueno H, Kobayashi R (2020) Correlation between the numbers of rotation steps in the ATPase and protonconducting domains of Fand V-ATPases. Biophys Rev 12(2):303-307

Okamoto K (2020) From a young BSJ member: advanced technologies encouraged me to dive into biophysics field. Biophys Rev 12(2): 205-206

Okazaki K, Papagiannakopoulos T, Motohashi H (2020) Metabolic features of cancer cells in NRF2 addiction status. Biophys Rev 12(2): 435-441

Olson WK (2020) Biophysical reviews' "Meet the Editors Series"-a profile of Wilma K. Olson. Biophysical Reviews 12(1):9-12

Pandzic E, Morkel CA, Li A, Cooke R, Whan RM, dos Remedios CG (2020) Nanomolar ATP binding to single myosin cross-bridges in rigor: a molecular approach to studying myosin ATP-kinetics using single human cardiomyocytes. Biophys Rev 12(4):1031-1040

Petchiappan A, Naik SY, Chatterji D (2020) Tracking the homeostasis of second messenger cyclic-di-GMP in bacteria. Biophys Rev 12(3): 719-730

Pratt S, Hernandez-Ochoa E, Martin S (2020) Calcium signaling: breast cancer's approach to manipulation of cellular circuitry. Biophysical Reviews 12(6) Current Issue

Pruna M, Ehler E (2020) The intercalated disc - a mechanosensing signalling node in cardiomyopathy. Biophys Rev 12(4):931-946

Raghunathan S, Jaganade T, Deva PU (2020) Urea-aromatic interactions in biology. Biophys Rev 12(1):65-84

Rajendra P. and Brahmajirao V. (2020) Modeling of dynamical systems through deep learning. Biophysical Reviews. 12(6) Current Issue

Sako Y (2020) SEIBUTSU BUTSURI, the official Japanese journal of the biophysical Society of Japan. Biophys Rev 12(2):215-216

Scimago (2020) Elsevier Scientific Journal Rankings List (journal position and metrics). https://www.scimagojr.com/journalrank.php? category=1304 https://www.scimagojr.com/journalsearch.php?q= $19400158558 \&$ tip $=$ sid\&clean $=0$

Shechtman Y (2020) Recent advances in point spread function engineering and related computational microscopy approaches: from one viewpoint. Biophysical Reviews 12(6) Current Issue

Suzuki M, Plakhotnik T (2020) The challenge of intracellular temperature. Biophys Rev 12(2):593-600

Takano M. Yura K., Ueda T. and Yasuda K. (2020) Biophysics at Waseda University Biophysical Reviews 12(2) 225-232

Tsuchiya Y, Tomii K (2020) Neural networks for protein structure and function prediction and dynamics analysis. Biophys Rev 12(2):569 573

Tsumoto K, Sakuta H, Takiguchi K, Yoshikawa K (2020) Nonspecific characteristics of macromolecules create specific effects in living cells. Biophys Rev 12(2):425-434

Uchihashi T, Ganser C (2020) Recent advances in bioimaging with highspeed atomic force microscopy. Biophys Rev 12(2):363-369 
Uda S (2020) Application of information theory in systems biology. Biophys Rev 12(2):377-384

van Dijk S (2020) The Sydney Heart Bank: a core facility that goes the extra mile to advance cardiac research. Biophys Rev 12(4):771-772

White SJ, Chong JJH (2020) Growth factor therapy for cardiac repair: an overview of recent advances and future directions. Biophys Rev 12(4):805-815

Yamaoki Y, Nagata T, Sakamoto T, Katahira M (2020) Recent progress of in-cell NMR of nucleic acids in living human cells. Biophys Rev 12(2):411-417

Yasuda K (2020) Dominant rule of community effect in synchronized beating behavior of cardiomyocyte networks. Biophys Rev 12(2): 481-501

Yokoyama Y, Terada T, Shimizu K, Nishikawa K, Kozai D, Shimada A, Mizoguchi A, Fujiyoshi Y, Tani K (2020) Development of a deep- learning-based method to identify "good" regions of a cryo-electron microscopy grid. Biophys Rev 12(2):349-354

Yusuf M, Farooq S, Robinson I, Lalani E (2020) Cryo-nanoscale chromosome imaging - future prospects. Biophysical Reviews 12(5): $1257-1263$

Zapotoczny B, Braet F, Wisse E, Lekka M, Szymoński M (2020) Biophysical Nanocharacterization of liver sinusoidal endothelial cells through atomic force microscopy. Biophys Rev 12(3):625-636

Zidovska A (2020) The rich inner life of the cell nucleus: dynamic organization, active flows and emergent rheology. Biophysical Reviews 12(5):1093-1106

Publisher's note Springer Nature remains neutral with regard to jurisdictional claims in published maps and institutional affiliations. 